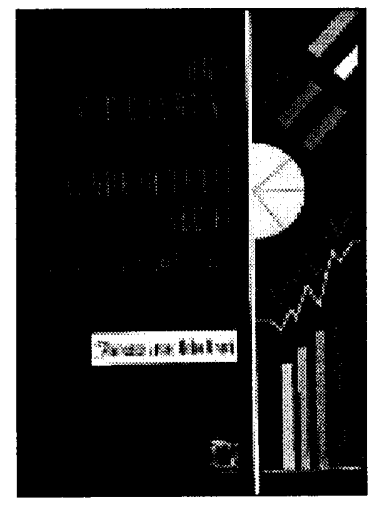

\section{O Pensamento de Habermas Posto à Disposição do Movimento Sanitário}

Agir Comunicativo e Pensamento Social - Uma Crítica ao Estratégico - Francisco Javier Uribe Rivera.

Rio de Janeiro: Ed. FIOCRUZ. 1995.

213 páginas.

Luiz Carlos de Oliveira Cecílio

Departamento de Medicina Preventiva e Social/FCM/Unicamp
Poucos trabalhos produzidos na Academia, nos últimos anos, são tão ricos de indicações para uma reflexão inovadora sobre nossas práticas institucionais como esta Tese de Doutoramento de Francisco Javier Uribe Rivera, publicada pela Editora FIOCRUZ. Nela, o autor faz uma competente incursão pelo universo habermasiano, dali "garimpando" um conjunto de idéias que contribuem de maneira expressiva para iluminar o intricado mundo das organizações de saúde. Seu maior mérito: não se "perder" nesta sua pesquisa, um estudo teórico de natureza comparativo-constrastante, na medida em que consegue explicitar, como fio condutor de sua pesquisa, um conjunto de questōes que são bastante coeren es com sua linha anterior de investigação. Não há como não reconhecer - para quem conhece os outros trabalhos do autor -, uma certa "crítica da crítica", muito saborosa e oportuna nesta sua última obra. Nela, as formulações de Carlos Matus e Mario Testa utilizadas, até então, como referência para uma crítica do planejamento normativo e de cunho economicista - são 
agora objeto de uma avaliação mais problematizadora e cuidadosa à luz das idéias do contemporâneo filósofo da Escola de Frankfurt. E não há aqui, nesta (re)releitura, nenhuma veleidade que se possa adjetivar de puramente acadêmica, mas um evidente compromisso "militante" com a busca de novas possibilidades de se pensar o planejamento e a gestão na Saúde.

O conceito central que Rivera extrai da obra de Habermas é o da "Racionalidade Comunicativa", que seria uma ampliação do conceito weberiano de racionalidade da ação, ainda preso, segundo este último, ao paradigma finalístico da filosofia da consciência. Mais especificamente, Habermas postula a possibilidade de uma fundamentação objetiva, de uma universalização das questões normativo-valorativas, baseada no uso de razões, argumentos ou interpretações críticas, de caráter vinculante, que Weber não admite. Este é o ponto. Para Rivera, "o subjetivismo cognitivo - instrumental da racionalidade normativa de Weber - tem sido questionado por Habermas, por apresentar uma ética dos fins últimos e não uma ética de responsabilidades: os agentes absolutizariam as causas em que se empenham, sem considerar as consequiencias sociais ou efeitos que para os outros ou para si própri- os poderiam gerar determinadas intençôes (quando tomadas no sentido de um racionalismo metafísico individual, absolutamente normativo). Esta concepção da ação normativa denunciaria um déficit de racionalidade. Trata-se de uma racionalidade da ação segundo a qual os agentes se desobrigam de prestar contas em público de suas intenções e modos de fazer, não atentando para as conseqüências possíveis de seus atos. Nesta perspectiva, os sujeitos não se co-responsabilizam pelo desempenho de determinadas intenções. Dito de outra forma, estas pretensões não estão submetidas ao critério de "consenso ensejado comunicativamente".

De certa forma, o parágrafo anterior fundamenta todas as preocupações e indagações que serão apresentadas no decorrer do livro. Estaria em jogo a possibilidade da reconstrução das relações entre os homens com base em uma nova ética, qual seja, aquela que privilegia a construção de consensos intermediados pelo uso da linguagem, baseados no entendimento, o que exigiria determinadas pressuposiçôes ideais de toda práxis comunicativa: simetria, não-coerção, autenticidade e verdade. "O conceito de ação comunicativa pressupõe a linguagem como um meio no âmbito do qual tem lugar um determinado processo de entendi- mento, em cujo transcurso os participantes, ao relacionarem-se com o mundo, apresentam-se uns perantes os outros com pretensões de validade que podem ser reconhecidas ou questionadas".

O caminho que Uribe Rivera compartilha com o leitor, após a apresentação de uma conceituação muito precisa do agir comunicativo ou da racionalidade comunicativa, é o de reconstruir (com bastante rigor e competência) a "desidealizaçào" a que Habermas submete sua "pragmática formal (teoria do significado dos atos lingüísticos), vinculando-a, empiricamente, a uma teoria social". Agora, o esforço é no sentido de pensar uma teoria social baseada no reconhecimento de uma coexistência tensa e dialética entre duas racionalidades opostas: a do mundo da vida e a do sistema. Mundo da vida entendido como o "horizonte onde se situa uma ação. É o ambiente apreendido onde se situa uma ação. (...) O conjunto de referências que os agentes constróem lingüisticamente e acumulam serviria para orientar a compreensão de cada ação nova (no caso, de cada novo ambiente situacional) (...) o conjunto de referências culturais e de outro tipo que permite interpretar os componentes internos de uma situação de ação (...) o celeiro de interpretações acumuladas ou de re- 
cursos que permite a definição de uma situação de ação a partir dos fins dos agentes (...)". Ou, na síntese estabelecida pelo autor: "O mundo da vida corresponde, por conseguinte, à linguagem e ao reservatório cultural em cujo contexto os sujeitos desenvolvem a interpretação de uma situação e uma situação correlata". O mundo da vida configura os contextos de integração do agir comunicativo, representados pela educação, família, associações normativas livres, meios de comunicação espontâneos, religião etc. Já o sistema configura os contextos de agir estratégico, que se identificariam com o mercado econômico e os sistemas de poder administrativo (o Estado).

$\mathrm{Na}$ construção teórica habermasiana, mundo da vida e sistema são duas ordens institucionais que correspondem a duas formas básicas de integração (coordenação) da ação: a integração social e a integração sistêmica. A primeira efetivada através do agir comunicativo (pela linguagem), já a segunda realizada mediante os médiuns (no sentido em que Parsons utiliza): dinheiro, poder, status e liderança moral. A teoria da modernidade de Habermas fala tanto de uma racionalização crescente do mundo da vida, traduzida em uma diferenciação de seus componentes (cultura, sociedade e perso- nalidade), como de uma progressiva colonização do mundo da vida pelo sistema. Predomina aqui uma certa visão pessimista, na medida em que o autor reconhece uma penetração permanente do mundo da vida pela "lógica" do sistema, ou seja, a "força da grana" (e do poder e do status...) contra a possibilidade de construção de um mundo baseado no entendimento e na solidariedade. Rivera tenta complexificar (com sucesso) a discussão a respeito desta tensão dialética entre as duas ordens institucionais, procurando estabelecer tanto um contraponto com a teoria marxista, como tentando explicitar as possibilidades e limites postos pela teoria social que Habermas constrói a partir do conceito de agir comunicativo. É o próprio Rivera que nos alerta para o fato de que "apesar do quadro sombrio, Habermas acredita firmemente na pervivência da racionalidade comunicativa em determinados nichos situados nas costuras entre o sistema e o mundo da vida". Aponta, como justificativa para um certo otimismo, a institucionalização jurídica da sociedade moderna, traduzida no reconhecimento do direito de cidadania e a institucionalização dos direitos sociais, via legislação social.

Tomando como pressuposto o fato de que a teoria social de Habermas pode ser aplicada à discussão da teoria das organizações, o autor defende a seguinte idéia: "as organizações como subsistemas sociais podem ser representadas como detentoras de duas racionalidades concorrentes que correspondem às duas formas de integração referidas por Habermas. De um lado, uma organização pode ser analisada do ponto de vista da teoria da ação comunicativa como locus do conjunto de significados que os atores organizacionais atribuem à sua práxis, ou seja, como a sede de conexões de sentidos que os atores constróem e procuram negociar em um contexto dialógico caracterizado pela multiplicidade de pontos de vista e por uma atitude orientada pelo entendimento. Nesta perspectiva, o contexto valorativo, normativo e subjetivo que envolve os atores, e que se define externa e internamente às organizações desempenha um papel relevante na orientação da ação. Por um outro lado, as organizações podem ser entendidas do ponto de vista estritamente cognitivo-instrumental como formas de racionalidade sistêmico-estratégica que transcendem a orientação particular dos atores, e que, portanto, subtraem os elementos normativos e subjetivos de toda a ação". Esta afirmação de Rivera funciona como linha-mestra da revisão crítica que faz da Teoria Geral da 
Administração e riquíssima de indicações para todos nós que temos, de uma forma ou de outra, tentado decifrar as "caixas pretas" que são as organizações de saúde.

Esta racionalidade sistêmico-estratégica é a que predomina tanto na organização pensada a partir do modelo burocrático, como na concepção sistêmico-contigencial, na medida em que o homem é considerado como "homem funcional", como instrumento da organização. Segundo tal concepção, ao empregado não restaria outra opção que a de cumprir ou de se adaptar a funções previamente objetivadas. Aos dois paradigmas hegemônicos dentre os macro-modelos de teoria organizacional (o burocrático e o sistêmicocontigencial, coincidentes na visão dos trabalhadores como "agentes" ou meros apêndices da organização), Uribe Rivera tenta contrapor um terceiro, por ele denominado "por força do programa de trabalho" de comunicativo. Para delinear este paradigma "alternativo" o autor se utiliza, centralmente, dos trabalhos de Silverman e de Kenneth Benson, nos quais "as organizações são definidas por ações de pessoas que transmitem significados umas às outras e que, em conjunto, estabelecem e revêem suas finalidades". A abordagem das organizações, a partí da teoria da ação de
Silverman, se dá no sentido de considerá-las como "sistemas competitivos de interpretação e neles buscando a explicação para a manutenção ou para a mudança dos sistemas organizacionais". Em Benson, em sua abordagem dialética das organizações, o autor destaca que estas representam "arranjos sociais", sempre provisórios, que se definem a partir da "multiplicidade de interesses contraditórios dos indivíduos e grupos organizacionais supondo a possibilidade de entendimento". Formulações de outros autores, como Kliksberg, são apontadas para reforçar a idéia de que as organizaçòes devem ser entendidas, antes de mais nada, como arenas permanentes de negociação e conflito.

Em Offe, Rivera destaca a discussão que este empreende a respeito das três racionalidades que coexistiriam no interior das organizações: a burocrática, a teleológica e a do consenso político. Como reconhece não ser possível visualizar uma racionalidade hierárquica que integre as premissas das mesmas, o autor afirma ser a administração "um campo problemático em que dificilmente se atingem e se articulam harmoniosamente todas as finalidades nela implícitas". De qualquer forma, vai tomar emprestado, do mesmo autor, a idéia da crescente dependência da adminis- tração em relação à função do consenso ("politização da administração"), principalmente no setor social, no qual, segundo Rivera, dar-seia a unidade entre produção e consumo, e onde a produção não poderia ser objetivizada nos moldes clássicos da economia. Para Offe, "a tarefa de obter consenso e harmonizar interesses se coloca para a administração não só quando se torna necessário abrandar pela negociação a resistência de grupos antagônicos com poder de veto e pressão, mas também em relação sua própria clientela, ou ainda na relaçâo com seu meio ambiente interno, com os membros da administração com seus interesses e concepções de valor, de ordem profissional, econômica e política". E qual leitor, cuja prática tenha se voltado para o interior das organizações de saúde, da mais "simples" unidade ambulatorial ao mais complexo hospital, poderia deixar de concordar, inteiramente, com a afirmação transcrita ? Pois, quando se trata de realizar a gestão de organizações ditas "profissionais", ou seja, aquelas nas quais os "de baixo" têm grande autonomia e poder, a atenção de consensos negociados é, na maioria das vezes, a única estratégia possível para se conseguir a cooperação da "base" para um determi- 
nado projeto que se queira conduzir.

É somente no último capítulo do livro que Rivera vai se ocupar, de forma mais sistematizada, em demonstrar aquilo que considera como premissa geral da sua investigação, qual seja, a de que "a planificação precisa alargar sua racionalidade. Entendida tradicionalmente como atividade racional de apoio à racionalização fina-lística no sentido weberiano da produção de uma eficácia econômica ou política, a planificação deveria ser considerada precipuamente uma forma de racionalidade comunicativa". Aqui, o autor, valoriza a legitimidade dos planos (apoiada nas normas e valores dos grupos sociais), muito mais do que uma possível viabilidade política dos mesmos. Esta é a moldura dentro da qual faz sua (re)leitura crútica da obra de Matus e Testa.

Em relação ao primeiro, é impossivel não perceber o cuidado com que Uribe Rivera faz suas observaçôes, até porque Matus ainda é uma referência muito importante para as atividades de docência e pesquisa desenvolvidas pelo grupo do Departamento de Planejamento e Administração da ENSP/ FIOCRUZ, ao qual o autor se vincula como Professor Adjunto. Vejamos alguns dos aspectos que uma leitura harbemasiana do planeja- mento estratégico situacional, feita pelo autor, põe em destaque:

- Haveria, em Matus, uma visão ainda muito tradicional (apesar clas "flexibilizações" propostas por Althusser e Poulantzas, autores nos quais se fundamentaria) das relaçôes base/superestrutura, na medida em que "a própria fenoestrutura, como superestrutura específica e imediata, deriva da estrutura econômica; é um fenômeno em relaçào à essência ou uma função em relação à estrutura".

- Matus utilizaria, na taxonomia da açào social que adota, uma variante "híbrida" de ação que seria, por essência e definição, contraditória e confusa, ao fazer uma improvável "mistura" de agir comunicativo com agir estratégico. É o que Matus batiza com o nome de ação estratégico-comunicativa.

- Nas formulações matusianas haveria a preocupação com a mediação ou comparabilidade do poder dos vários atores em disputa, o que suporia a redução do mesmo a um elemento objetivo. Para Rivera, "descontando que essa comparação traz resultados duvidosos (como Habermas afirma), o problema mais sério da mesma (do ponto de vista metodológico) diz respeito ao fato de que os atores escolhem recursos diferenciados para exercer pressão sobre os pro- jetos em conflito".

A sintese que o autor faz desta leitura habermasiana é de que "Matus não tira o devido proveito de uma parte de sua heterogênea matriz teórica, a saber, dos fundamentos do conceito de situação (que se identificam com variantes da filosofia da existência, da hermenêutica gadameriana $\mathrm{e}$ do interacionismo simbólico) e, da teoria da ação de Habermas, recolhendo-se, operacionalmente a uma postura estratégica que absolutiza o conflito e que demonstra às vezes traços objetivadores. Derivamos daí a necessidade do planejamento situacional revalorizar as estratégias de negociação e de cooperação, em prol da legitimidade dos planos; isto implica assumir uma perspectiva mais descentralizada de mundo, trazendo à tona o mundo social dos atores para além da fria compreensão do planejamento enquanto uma tecnologia que opera situações e regularidacles empíricas (passíveis de uma quantificação e operacionalização)". Como contraponto a esta avaliação, Rivera aponta para as possibilidades de uma leitura do plano enquanto estrutura comunicativa, ao reconhecer o caráter "compromissário" das regulações inerentes ao plano e, desta forma, um certo conteúdo normativo (no sentido habermasiano). Reconhece até que as idéias de descentralização e planejamento partici- 
pativo, conforme propostas por Matus, em contraposição ao conceito de cálculo estratégico, seriam uma espécie de "disjunção analítica deliberada", presente na obra matusiana.

Em relação à obra de Mario Testa, o autor avalia que o mesmo "revaloriza o componente interativo-comunicacional do planejamento, fazendo eco à pregação habermasiana, mas tenta fundamentar esse componente em uma visão bipolarizada de classe da ordem social, dominada pela produção econômica. Desta maneira, sim- plifica o jogo dos atores e o condiciona a um movimento sistêmico, convicto de que o trabalho poderá produzir uma ordem comunicativa não deformada e livre do Poder. Democracia é, nesta acepção, uma expressão ideologizada da classe dominada"

O autor, à guisa de finalização do seu trabalho, aponta para as imensas possibilidades de utilização de modelos de negociação cooperativa ao nivel das organizações de saúde, abrindo um leque heterodoxo de abordagens e enfoques teórico-metodológicos, que vão descle as formulações de Bandler e Grinder, até a compreensão das organizações enquanto fenômeno lingüístico, conforme vem sendo trabalhado por Fernando Flores.

Fica da leitura deste livro, o irrecusável convite, como o próprio Rivera aponta, de um estudo mais sistemático das experiências de gestão democrática de serviços de saúde, em curso no Brasil, para que se possa pensar, a partir do salutar encontro da teoria com a prática, em novas possibilidades de gestão da Saúde. 